\title{
Vivido paterno do filho prematuro hospitalizado por meio do registro fotográfico
}

\author{
Paternal living of premature son hospitalized through photographic record \\ Vida paterna de hijo prematuro hospitalizado mediante registro fotográfico
}

Ludmilla Laura Miranda ${ }^{1}$ (i) Rosangela Aparecida Pimenta Ferrari ${ }^{2}$ (1) Rosana Claudia de Assunção ${ }^{3}$ (1) Adriana Valongo Zani² (D)

1. Universidade Estadual de Londrina, Programa em Enfermagem. Londrina, PR. Brasil.

2. Universidade Estadual de Londrina, Departamento de Enfermagem. Londrina, PR. Brasil.

3. Instituto Federal do Paraná. Londrina, PR. Brasil.

\section{Resumo}

Objetivo: compreender o mundo vivido do pai que possui um filho pré-termo hospitalizado por meio do registro fotográfico. Método: estudo qualitativo fundamentado no referencial teórico-metodológico da Fenomenologia Social de Schütz. Participaram deste estudo nove pais que possuíam filhos internados em uma das duas unidades neonatais (UTIN/UCI), com idade gestacional inferior a 37 semanas, cujo nascimento ocorreu no período de novembro de 2018 a abril de 2019. Resultados: após a análise e a interpretação dos dados coletados, emergiram duas unidades temáticas: Vivenciando momentos da hospitalização do filho pré-termo "motivos por que", que resultou na categoria Privilégio em registrar a evolução do filho pré-termo; O que almejar do registro fotográfico frente ao momento de hospitalização do filho pré-termo "motivos para", que resultou nas categorias Felicidade: uma alegria em cada registro; Lembranças: o recordar em cada registro. Considerações finais: o uso do registro fotográfico mostrou ser um método que oportunizou compreender que o pai deseja estar próximo ao filho e vivenciar o momento de hospitalização. Desse modo, é necessário que os profissionais desenvolvam estratégias que possibilitem, ao pai, o exercício da paternidade e promovam o vínculo com o seu filho na unidade neonatal.

Descritores: Pai; Recém-nascido Prematuro; Enfermagem Neonatal; Fotografia; Humanização do Atendimento.

\section{Abstract}

Objective: to understand the experienced world of the father of a hospitalized preterm child through a photographic record. Method: this qualitative study was based on the theoretical and methodological framework of Schütz's Social Phenomenology. Nine parents with children admitted to one of the two neonatal units (NICU/ICU), with gestational age below 37 weeks, whose birth occurred between November 2018 and April 2019, participated in this study. Results: after the analysis and interpretation of the data collected, two thematic units emerged: Experiencing moments of the preterm child's hospitalization "reasons why", which resulted in the category Privilege in recording the evolution of the preterm child; What to look for in the photographic record when facing the moment of hospitalization of the preterm child "reasons why", which resulted in the categories Happiness: a joy in every record; Memories: remembering in every record. Final considerations: the use of photographic records proved to be a method that provided the opportunity to understand that the father wants to be close to his child and experience the moment of hospitalization. Thus, it is necessary that professionals develop strategies that enable the father to exercise paternity and promote the bond with his child in the neonatal unit.

Keywords: Father; Premature Newborn; Neonatal Nursing; Photography; Humanization of Care.

\section{Resumen}

Objetivo: comprender el mundo vivido del padre que tiene un hijo prematuro hospitalizado a través del registro fotográfico. Método: estudio cualitativo basado en la referencia teórico-metodológica de la Fenomenología social de Schütz. Nueve padres participaron en este estudio que tenían niños ingresados en una de las dos unidades neonatales (UTIN/UCI), con una edad gestacional de menos de 37 semanas, cuyo nacimiento ocurrió entre noviembre de 2018 y abril de 2019. Resultados: Después de analizar e interpretar los datos recopilados, surgieron dos unidades temáticas, la primera: Experimentar momentos de hospitalización del hijo prematuro "razones por las cuales", lo que resultó en la categoría Privilegio al registrar la evolución del hijo prematuro. La segunda unidad: qué buscar en el registro fotográfico frente al momento de la hospitalización del hijo prematuro "razones para", lo que resultó en dos categorías: Felicidad: una alegría en cada registro; Memorias: el recuerdo en cada registro. Consideraciones finales: el uso del registro fotográfico demostró ser un método que nos permitió comprender que el padre quiere estar cerca de su hijo y experimentar el momento de la hospitalización. Por lo tanto, es necesario que los profesionales desarrollen estrategias que permitan al padre ejercer la paternidad y promover el vínculo con su hijo en la unidad neonatal.

Palabras clave: Padre; Recién Nacidos Prematuros; Enfermería Neonatal; Fotografía; Humanización del atendimiento.
Autor correspondente: Ludmilla Laura Miranda. Email: m.ludmilla@hotmail.com.

Recebido em 17/08/2020.

Aprovado em 15/02/2021.

DOI:https://doi.org/10.1590/2177-9465-EAN-2020-0314 


\section{INTRODUÇÃO}

O cuidado com o filho, durante muito tempo, foi responsabilidade exclusiva da mãe, porém, no decorrer dos anos, essa distribuição de papéis no contexto familiar vem se alternando e o pai já não é mais considerado apenas o responsável pelo sustento da família. ${ }^{1,2}$

Este fato deve-se às mudanças históricas da parentalidade que ocorreram no transcorrer dos anos em decorrência das transformações socioeconômicas e culturais. A sociedade ocidental sofreu modificações significativas desde o modelo patriarcal, em que toda a organização familiar se centra na figura masculina, até à multifacetada sociedade pós-moderna, com novos modelos de família. A paternidade deixou de abranger apenas o papel circunscrito à figura de provedor para também envolver comportamentos e atitudes de maior envolvimento e contato afetivo com os filhos associados a diferentes expectativas, crenças e atitudes de cada gênero no contexto familiar. ${ }^{3}$

Diante desse novo contexto, no período gestacional, os pais idealizam o nascimento de um filho a termo e saudável. Entretanto, ao se deparar com um nascimento antecipado e o surgimento de um filho pré-termo e frágil, demonstram sentimentos de medo e insegurança diante da separação e da necessidade de hospitalização do filho. ${ }^{1,4}$

A Unidade de Terapia Intensiva Neonatal (UTIN) é considerada um ambiente não familiar, repleto de equipamentos desconhecidos, que pode gerar, nos pais, sentimentos como ansiedade e medo. Em contraponto, eles compreendem que este ambiente pode ser capaz de minimizar o impacto que o filho sofre ao sair antecipadamente do útero materno e, assim, elevar suas chances de sobrevida. ${ }^{5,6}$

A participação do pai durante a internação do seu filho é imprescindível, principalmente por ser considerado uma figura de apoio e amparo para a mãe e o recém-nascido. Para alguns pais, a parentalidade emerge após o início do contato e a interação com o bebê, portanto, sua entrada nas unidades de internação deve ocorrer sem imposição de horários pré-estabelecidos. Trata-se de um direito e não uma visita permitida pela equipe de saúde ou instituição, facilitando, assim, o vínculo entre pai e filho. ${ }^{1,4,7}$

O pai deseja participar efetivamente dos cuidados de seu filho, porém, sente dificuldade em revelar suas percepções e sentimentos. Associado a isto, há a dificuldade dos profissionais de saúde em inseri-lo neste contexto, visto que o pai deve ser considerado protagonista nos cuidados da criança juntamente com sua companheira. .,9 $^{8}$

O registro fotográfico é um recurso pouco explorado na assistência de Enfermagem, mas vem auxiliando na compreensão de experiências vividas por pacientes, evoluções, tratamentos e acompanhamento de doenças. ${ }^{10}$

A utilização da fotografia favorece momentos de recordação referentes a situações vivenciadas, como a hospitalização da criança pré-termo e os momentos entre pai e filho, podendo, assim, contribuir para o processo de vinculação no contexto hospitalar na Enfermagem neonatal. Além disso, é uma importante ferramenta de prática em Enfermagem não apenas de modo técnico, como auxílio no tratamento de feridas e a organização do processo de trabalho, mas como estratégia para o registro de sentimentos e percepções do recém-nascido e sua família, fato este, às vezes, não visualizado pela comunicação verbal. ${ }^{11}$

Diante desse contexto, emergiu o seguinte questionamento: "Como o pai percebe a hospitalização do filho pré-termo por meio do registro fotográfico?".

Assim, neste estudo, buscou-se apoio no referencial da Fenomenologia Social de Alfred Schütz para dar suporte no que tange ao vivido paterno no seu cotidiano de hospitalização do filho prematuro, buscando a compreensão da realidade para descrever o fenômeno, neste caso, a experiência da utilização do registro fotográfico para representar a hospitalização do filho prematuro. ${ }^{12}$

Com o intuito de contribuir com a construção de estratégias de cuidado que possam privilegiar o recém-nascido prematuro e a sua família, este estudo teve como objetivo compreender o mundo vivido do pai que possui um filho pré-termo hospitalizado por meio do registro fotográfico.

\section{MÉTODO}

Trata-se de um estudo qualitativo, tendo como alicerce o referencial teórico-metodológico da Fenomenologia Social de Alfred Schütz, que permite, ao pesquisador, acessar a consciência da pessoa que vivencia o fenômeno estudado, salientando a relação social como elemento fundamental na interpretação dos significados humanos. Para Schütz, o homem desenvolve-se por meio da descrição de sua história de vida e recordações de experiências anteriormente vividas que certamente o impulsionarão em suas próximas ações. ${ }^{12}$

Schütz, por meio da pesquisa qualitativa, propõe uma investigação social para avaliar o comportamento das pessoas no mundo cotidiano. Essa compreensão na área da Enfermagem vem tornando-se um sinalizador do cuidado em saúde. ${ }^{13}$

Definida como "vivências conscientes intencionalmente relacionadas com o outro", o objeto do conhecimento é o mundo enquanto vivido pelo outro, "emergindo espontaneamente, com um caráter previamente projetado". Diante disso, a ação projetada possui significados subjetivos, intencionais e que podem se basear no passado, presente e futuro. ${ }^{14}$

Os "motivos porque" fazem parte das realizações passadas, já concluídas, e que podem influenciar as ações atuais. Fundamentado neste contexto, obteve-se o acesso ao cotidiano da ação dos pais e buscou-se captar o motivo de cada registro fotográfico realizado pelo pai durante a internação de seu filho na unidade neonatal para que pudesse captar os "motivos porque" de cada ação ${ }^{11} \mathrm{e}$, posteriormente, remetê-los ao seu futuro, ou seja, captar suas expectativas diante do contexto de internação do filho pré-termo (motivos para).

A pesquisa é integrada a um amplo projeto de pesquisa intitulado "A figura paterna no cuidado ao recém-nascido prematuro e de baixo peso hospitalizado em Unidade de Terapia Intensiva Neonatal", financiado pelo Conselho Nacional de Desenvolvimento Científico e Tecnológico (CNPq). 
O cenário do estudo foram as Unidades de Terapia Intensiva Neonatal (UTIN) e Cuidados Intermediários (UCI) de um hospital universitário da região norte do Paraná, sendo este credenciado ao Sistema Único de Saúde (SUS), caracterizando-se como instituição de caráter público. A UTIN e a UCI são compostas por dez leitos cada.

Participaram deste estudo nove pais que possuíam filhos internados em uma das duas unidades neonatais (UTIN/UCI), com idade gestacional inferior a 37 semanas, cujo nascimento ocorreu no período de novembro de 2018 a abril de 2019.

Foram considerados como critérios de inclusão: pais, maiores de 18 anos e que tinham contato diário com seus filhos no ambiente hospitalar. Como critérios de exclusão, foram estabelecidos pais que não assumiram a paternidade e bebês que recebessem alta em um período inferior a sete dias.

Dos dezenove pais que possuíam filhos pré-termos hospitalizados na unidade neonatal, no período da coleta, sete foram excluídos, pois não atendiam aos critérios de inclusão e três recusaram participação, referindo não se sentir à vontade para o manuseio do equipamento e o registro fotográfico.

Para a coleta, a priori, a pesquisadora principal entrava em contato telefônico ou pessoalmente diariamente com a unidade para a identificação de bebês prematuros e, após obter o contato deste pai, agendava um dia na unidade para que pudesse realizar a abordagem para a pesquisa. No dia, o pesquisador convidava o pai a participar da pesquisa para fotografar momentos com seu filho pré-termo que representem os significados atribuídos por ele ao contexto da hospitalização, explicando os objetivos do estudo.

Após os esclarecimentos da pesquisa e o assentimento do pai, era entregue uma máquina fotográfica e fornecia-se uma orientação de como manusear o equipamento e que os registros fotográficos eram livres, podendo fotografar o que desejasse e que remete ao momento da hospitalização do filho. Apenas havia a ressalva de não fotografar o ambiente hospitalar, procedimentos, profissionais ou outros bebês, salvo as exceções em que profissionais e/ou outras pessoas permitissem. Esses registros deveriam ser feitos durante o período de uma semana a partir da data de entrega e só podendo ser realizados pela máquina fotográfica fornecida pelo pesquisador.

Assim que o pai aceitava participar e recebia as orientações, o leito era identificado, informando que o bebê estava participando do projeto de registros fotográficos e seu pai tinha a permissão de fotografar momentos com seu filho na unidade, sem restrições de horários, em um período de uma semana.

Após o prazo de sete dias de registro, a pesquisadora retornava à unidade de internação, recolhia a máquina fotográfica e realizava o salvamento das imagens registradas em seu computador. Em outro momento, a pesquisadora entrava em contato por telefone e agendava um encontro, que ocorria em uma sala de reuniões dentro da própria unidade, para a realização da entrevista. Essa sala era reservada para que, no momento da entrevista, não ocorressem interrupções. No momento da entrevista, o pesquisador mostrava ao pai, por meio de um notebook, todos os registros fotográficos feitos por ele. Em seguida, iniciava a entrevista com o auxílio de um instrumento semiestruturado contendo duas etapas, sendo que a primeira envolvia a caracterização do pai e a segunda continha as seguintes questões norteadoras: Como foi, para você, fotografar momentos relacionados à hospitalização do seu filho? O que você sentiu? O que você espera deste período de hospitalização do seu filho?

As entrevistas foram audiogravadas por meio de um smartphone e um caderno de campo para auxiliar o pesquisador nas observações que ocorressem durante a entrevista. A duração média das entrevistas com os pais foi de aproximadamente 30 minutos, considerando a interação inicial e a entrevista propriamente dita. Cabe ressaltar que as entrevistas foram encerradas ao se evidenciar convergências dos "motivos porque" e os "motivos para".

Ao término da entrevista, o pesquisador entregava um CD com todas as fotografias realizadas pelo pai e solicitava que ele escolhesse uma para que fosse revelada e entregue na semana seguinte.

Para a organização e a análise do material qualitativo, cumpriram-se os seguintes passos: $1^{\circ}$ - leitura atentiva e criteriosa de cada depoimento na íntegra para apreender o sentido global da experiência vivida pelos pais/homens; $2^{\circ}$ - releitura de cada depoimento para identificar aspectos comuns que expressam os conteúdos relacionados aos "motivos por que" e "motivos para"; $3^{\circ}$ - agrupamento dos aspectos comuns conforme a convergência de conteúdos para a composição das categorias concretas; $4^{\circ}$ - análise das categorias para a compreensão da experiência vivida pelos pais/homens; $5^{\circ}$ - constituição do tipo vivido a partir do conjunto de "motivos por que" e "motivos para" expressos na análise das categorias; $6^{\circ}$ - discussão do tipo vivido à luz da Fenomenologia Social.

Cabe salientar que o estudo foi norteado pelos princípios da Resolução do Conselho Nacional de Saúde no 466/12, que regulamenta as pesquisas envolvendo seres humanos. $A$ pesquisa foi realizada após a aprovação pelo Comitê de Ética em Pesquisa sob o Parecer $n$ ㅇ 694.303. Os participantes assinaram o Termo de Consentimento Livre e Esclarecido (TCLE) e o termo de autorização do uso de imagens registradas por eles. Para preservar o anonimato dos pais, as descrições das falas estão apresentadas utilizando-se a Letra $P$, de pai. Em seguida, colocou-se o número correspondente à ordem de execução das entrevistas.

\section{RESULTADOS}

Os nove pais participantes enquadraram-se na faixa etária compreendida entre 18 a 35 anos e possuíam relacionamento conjugal estável com as mães dos bebês. Quanto ao nível de escolaridade, cinco possuíam Ensino Médio incompleto, três, Ensino Médio completo e um, Ensino Superior incompleto. Destes, cinco estavam vivenciando, pela primeira vez, a paternidade. Em relação ao nível socioeconômico, seis referiram baixa renda (renda 
familiar per capita de até meio salário-mínimo - $\mathrm{R} \$ 1.245,30)$ e três, média renda (rendimento mensal $\mathrm{R} \$ 5.088,70$ ). ${ }^{15}$

Quanto aos recém-nascidos, quatro eram do sexo masculino e cinco, do feminino. A idade gestacional variou de 32 a 36 semanas e o tempo médio de internação foi de 25 dias.

Em relação à rotina das unidades cenário de estudo, no que tange à permanência dos pais na unidade, elas guiam-se pelo princípio do cuidado centrado na família e cumprem a lei de garantia de acompanhante. Os pais podem permanecer por um período de 24 horas na unidade, independentemente de seu filho estar em cuidados intensivos ou não. Estratégias de cuidado como a posição canguru e cuidados simples, tais como a troca de fralda, a higiene oral ou perineal, a realização de banho quando próximo à alta, o incentivo à amamentação como a ordenha de leite à beira-leito e o oferecimento de leite fresco, são cuidados já instituídos na unidade e acolhidos pela equipe multiprofissional.

A Fenomenologia Social de Alfred Schütz possibilitou a compreensão da vivência do pai em fotografar momentos relacionados à hospitalização do seu filho pré-termo não de forma singular e individualizada, mas no contexto das relações sociais.

Desse modo, após a análise e a interpretação dos dados coletados, emergiram duas unidades temáticas: Vivenciando momentos da hospitalização do filho pré-termo "motivos por que", que resultou na categoria Privilégio em registrar a evolução do filho pré-termo; O que almejar do registro fotográfico frente ao momento de hospitalização do filho pré-termo "motivos para", que resultou nas categorias Felicidade: uma alegria em cada registro; Lembranças: o recordar em cada registro.

\section{Vivenciando momentos da hospitalização do filho pré-termo "motivos por que"}

Entre os "motivos por que", apreendeu-se o concreto vivido pelo pai ao registrar os momentos da hospitalização do filho pré-termo.

\section{Privilégio em registrar a evolução do filho pré- termo}

O pai enfrenta diversas dificuldades, como o retorno ao trabalho com menos de uma semana, as restrições de horários de visita e as rotinas impostas pela unidade, impossibilitando-o de registrar imagens dos filhos quando desejasse. A unidade segue uma rotina, permitindo o uso de celulares ou câmeras fotográficas pelos pais para registros apenas durante um dia na semana, impossibilitando o registro diário conforme o depoimento a seguir.

Eu me senti bem em tirar as fotos já que eu não poderia tirar com meu celular. Com a máquina, eu me senti à vontade. (P2)

Tirar fotos me ajudou a me sentir útil porque tudo que eu ia fazer eu não podia. (P1)
Ao mesmo tempo em que os pais relatam dificuldades enfrentadas para permanecer na unidade, eles descrevem as motivações que os fazem continuar ali ao lado dos seus bebês.

Estimulante! Principalmente para mim, que sou pai e já volto a trabalhar amanhã e não tinha nenhuma fotinha dele. Com essa câmera, pude registrar quantas eu quis. [risos] (P6)

Uma conquista, pois não são todos os pais que tiveram essa oportunidade e eu tive [...] fiquei muito feliz porque, até então, eu só tinha foto de quando ele nasceu, depois, não pude mais tirar. (P8)

Eu consegui registrar a melhora dele. (P5)

\section{0 que almejar do registro fotográfico frente ao momento de hospitalização do filho pré-termo "motivos para" Felicidade: uma alegria em cada registro}

De modo geral, a internação de um filho gera sentimentos negativos como tristeza e impotência, no entanto, os momentos em que o pai realizava os registros fotográficos possibilitaram a emersão de sentimentos positivos como a felicidade. Os pais têm em vista que os momentos de contato com o bebê na unidade neonatal produzem uma sensação de cuidado e, quando associado à oportunidade de realizar os registros fotográficos dos seus filhos, emite sentimentos de alegria e satisfação.
Muito bom, maravilhoso[...] eu fiquei bem feliz com essa iniciativa do projeto. (P2)
Eu fiquei muito feliz! (P3)
Eu me senti bem, muito feliz em estar registrando todos os momentos dele naquele lugar. (P6)
Foi incrivel, eu me senti feliz! (P5)
Eu me senti bem, era uma maneira de eu ficar mais pertinho dele. (P8)

A fotografia fez com que eu ocupasse a minha cabeça $e$ parei de pensar em coisas ruins[...] e me senti útil. (P1)

\section{Lembranças: o recordar em cada registro}

Em relação aos registros fotográficos, os pais verbalizaram que as imagens possibilitaram lembranças de momentos únicos, que serão guardados por toda a vida, de um período difícil da hospitalização do filho.

Eu adorei e minha esposa mais ainda, pois vamos ter lembranças para o resto da vida [...]. (P4)

Foi bom! Vamos ter lembranças para mostrar para ele quando estiver "maiorzinho" e contar tudo que ele passou. (P7) 
Ao visualizar as imagens registradas por ele durante o processo de internação do bebê, o pai reconhece que, mesmo diante dos inúmeros problemas enfrentados durante a hospitalização, as fotos possibilitaram boas lembranças que merecem ser compartilhadas com seus filhos para ressaltar a sua força e superação.

\section{DISCUSSÃO}

No decorrer da internação do recém-nascido pré-termo, os pais almejaram acompanhar os momentos com o seu bebê, colaborar nos cuidados e ter participação efetiva na evolução. As experiências que os pais viveram dos momentos da hospitalização do filho pré-termo revelaram que a oportunidade de registrar, por meio da fotografia, a internação da criança permitiu que se sentissem úteis, pois, de alguma forma, estavam realizando algum cuidado com o filho e vivendo a sua paternidade. $O$ cuidado é uma ação vivida individualmente, mas inserida no mundo da vida social destes pais, sendo significado e ressignificado a partir dos momentos fotográficos. Assim, as rotinas impostas pela unidade, com dias pré-estabelecidos para a realização de fotografias, bem como as atividades profissionais, como o retorno ao trabalho pelo fim da licença-paternidade, foram amenizadas com a oportunidade de poderem registrar diversas fases com o seu filho na unidade neonatal. ${ }^{9,12}$

Schütz incentiva o despertar de um olhar mais detalhado e significativo que possa modificar todos os envolvidos no processo de cuidar. ${ }^{16}$ Este estudo, indiretamente, propiciou, aos pais, o privilégio de não possuírem dias preestabelecidos para o registro fotográfico, o que gera uma nova indagação sobre essa rotina da unidade de determinar dia para esse momento, uma vez que, para alguns pais, os momentos são únicos e não podem ser pré-determinados.

Um estudo realizado em uma maternidade do Rio de Janeiro enfatizou que o pai desempenha um papel importante durante o processo reprodutivo. Sua participação, durante a gestação, nascimento e puerpério, é de extrema importância, pois o genitor é visto como um protetor mesmo diante de um nascimento prematuro. ${ }^{17} \mathrm{~A}$ falta de conhecimento dos pais sobre o estado do filho, em decorrência da falha de comunicação no ambiente hospitalar neonatal, pode acarretar sentimentos de sofrimento e o consequente afastamento devido à dificuldade de fortalecimento de vínculo. $4,13,18$

Possibilitou-se, pela fotografia, considerando o contexto de experiências vivenciadas pelo pai frente à hospitalização do filho pré-termo, o surgimento de sentimentos de alegria (motivos para), que expressavam a intencionalidade mesmo diante das adversidades que a internação do bebê pudesse representar. A oportunidade de registrar momentos do recém-nascido na UTIN permitiu que o pai se sentisse mais próximo de seu filho e, consequentemente, emergiram sensações de bem-estar e segurança.

A presença do pai próximo ao RN pré-termo tem colaborado, de forma positiva, na evolução do bebê na UTIN. Esses contato $e$ cuidado auxiliam as respostas protetoras e fortalecem o vínculo entre pai e filho, pois o genitor exerce a função de um veiculador de comunicação do estado de saúde do filho. ${ }^{2} \mathrm{Na}$ literatura, foram encontrados resultados semelhantes em estudos nacionais e internacionais sobre a temática do apoio, evidenciando a sua importância durante os processos. ${ }^{2,4,19,20}$ Cuidar requer 0 estabelecimento de uma relação face a face, que Schütz define como aquela na qual os sujeitos envolvidos estão conscientes um do outro e voltados mutuamente, no mesmo tempo e espaço. ${ }^{16}$

Os pais necessitam ser protagonistas dos cuidados de seus filhos em uma UTIN, porém, ainda são vistos como coadjuvantes, principalmente após a chegada da mãe neste cenário, passando a ter seu acesso restrito a horários de visitas. ${ }^{1,2,7,9}$

Oregistro fotográfico proporcionou que estes pais pudessem voltar o seu pensamento apenas para momentos considerados felizes e bons como uma distração para que sentimentos como tristeza e sofrimento não viessem à tona nesse momento.

Ter um bebê nascido prematuro representa um desafio para os pais. De um ponto de vista evolutivo, o investimento em crianças vulneráveis é menos gratificante do que investir em filhos fortes e saudáveis, quando consideradas as compensações pela criação dos filhos. Desse modo, o recém-nascido prematuro, devido às suas condições clínicas, como baixo peso e maior risco para complicações neurológicas, representa, para o homem, momento de insegurança, o que pode prejudicar o vínculo com o seu bebê, sendo necessário que os profissionais atuantes nas unidades neonatais insiram o genitor no cuidado ao filho pré-termo, que possui maior dificuldade de vinculação com o filho prematuro do que a mães. ${ }^{19} \mathrm{~A}$ ação social da Fenomenologia Social de Alfred Schütz é intencional e, neste estudo, observou-se que a fotografia emergiu como uma estratégia que possibilitou, para alguns pais, desenvolver e fortalecer esse vínculo durante a hospitalização, uma vez que relataram que realizar os registros fotográficos permitiu que ficassem mais próximos de seus bebês e, desse modo, pudessem vivenciar o cuidado ao filho. ${ }^{12,21}$

A compreensão da ação de cuidar dar-se-á, em maior profundidade, à medida que for pautada na reciprocidade de intenções e expectativas entre o ser cuidado, ou seja, o filho prematuro hospitalizado e o cuidador, no caso, o pai. As perspectivas recíprocas são construções típicas de objetos de pensamento que traduzem a apreensão desse objeto e seus aspectos conhecidos pelos pais no mundo social. ${ }^{16}$

O pai necessita de acompanhar a evolução de seu filho na UTIN para que demonstre amor, seus valores e princípios projetados. . $^{43,18}$

Além das imagens fotográficas possibilitarem um maior vínculo com o seu filho, outro aspecto positivo contextualizado pelos pais foi relacionado à fotografia proporcionar recordações que remeterão a lembranças de momentos únicos, considerados difíceis, vivenciados dentro da UTIN, porém, necessários para que o filho compreenda o milagre da vida.

Os pais/homens, ao se deparar com o nascimento de um recém-nascido pré-termo, depositam toda a sua confiança no cenário tecnológico de uma UTIN. Porém, esse mesmo ambiente, capaz de manter vivo o seu bebê, é o responsável pela interrupção dos primeiros contatos entre pai e filho., ${ }^{4,20}$ 
Outro fato importante está relacionado com a atual configuração familiar na qual é observado o surgimento de um modelo de pai mais afetivo e participante das atividades que remetem à família, o que contraria o modelo de paternidade hegemônico. ${ }^{1,2}$

A atividade de registrar as imagens fotográficas do filho pré-termo durante a hospitalização propiciou motivação, ou seja, um estímulo durante a compreensão do processo de cuidar. Tal fato contribui para uma maior permanência do pai na unidade, estimulando um maior vínculo afetivo e momentos de distração em situações consideradas incompreensíveis de serem enfrentadas. ${ }^{21}$

\section{CONSIDERAÇÕES FINAIS}

A compreensão do mundo vivido do pai que possui um filho pré-termo hospitalizado por meio do registro fotográfico permitiu identificar que esse pai iniciou a construção do vínculo com seu filho, mantendo-se mais tempo na unidade, condição que gerou bem-estar, e percebeu-se o quanto a sua presença foi útil e necessária para o seu filho.

Neste contexto, foi possível perceber que o registro fotográfico como estratégia permitiu apreender que o pai desejou estar próximo ao filho e vivenciar o momento de hospitalização. Desse modo, é necessário que os profissionais atuantes na unidade neonatal desenvolvam estratégias que possibilitem, ao pai, vivenciar a sua paternidade e desenvolver, de forma plena, o vínculo com o seu filho.

No entanto, é importante ressaltar que, apesar de o estudo possibilitar compreender o mundo vivido do pai de um recémnascido prematuro hospitalizado, apresenta, como limitador, o fato de ter sido realizado em apenas uma unidade que já possui inúmeras estratégias de inserção da família no cuidado ao recém-nascido prematuro, sendo necessários novos estudos abrangendo contextos diferentes relacionados à humanização da assistência em ambientes neonatais.

\section{FINANCIAMENTO}

Conselho Nacional de Desenvolvimento Científico e Tecnológico (CNPq), Processo no 448117/2014-2. Pesquisa com o título "A paterna no cuidado ao recém-nascido prematuro e de baixo peso hospitalizado em Unidade de Terapia Intensiva Neonatal (UTIN)", coordenado pela autora Adriana Valongo Zani.

\section{CONTRIBUIÇÃO DOS AUTORES}

Desenho do estudo. Ludmilla Laura Miranda.

Coleta ou produção dos dados. Ludmilla Laura Miranda. Adriana Valongo Zani.

Análise de dados. Ludmilla Laura Miranda. Adriana Valongo Zani. Rosangela Ap. Pimenta Ferrari. Rosana Claudia de Assunção.
Interpretação dos resultados. Ludmilla Laura Miranda. Adriana Valongo Zani Rosangela Ap. Pimenta Ferrari. Rosana Claudia de Assunção.

Redação e revisão crítica do manuscrito. Ludmilla Laura Miranda. Rosangela Ap. Pimenta Ferrari. Rosana Claudia de Assunção. Adriana Valongo Zani

Aprovação da versão final do artigo. Ludmilla Laura Miranda. Rosangela Ap. Pimenta Ferrari. Rosana Claudia de Assunção. Adriana Valongo Zani

Responsabilidade por todos os aspectos do conteúdo e a integridade do artigo publicado. Ludmilla Laura Miranda. Rosangela Ap. Pimenta Ferrari. Rosana Claudia de Assunção. Adriana Valongo Zani

\section{EDITOR ASSOCIADO}

Stela Maris de Mello Padoin

\section{REFERÊNCIAS}

1. Castro FM, Silva LJ, Soares RLSF, Christoffel M, Rodrigues EC. The first meeting of the father with baby preterm in the Neonatal Intensive Care Unit. Index Enferm [periódico na internet]. 2015;24(1):31-4. Disponível em: https://www.researchgate.net/publication/282982564_The_first meeting_of_the_father_with_baby_preterm_in_the_Neonatal_Intensive Care_Unit

2. Barcellos AA, Zani AV. Vivências do pai em face do nascimento do filho prematuro: revisão integrativa. J Health Biol Sci. 2017;5(3):277-85 http://dx.doi.org/10.12662/2317-3076jhbs.v5i3.1198.p277-285.2017.

3. Martins CA, Abreu WJCP, Figueiredo MCAB. Tornar-se pai e mãe: um papel socialmente construído. Rev Enf Ref. 2014;serIV(2):121-31.http:// dx.doi.org/10.12707/RIII1394.

4. Soares RLSF, Christoffel MM, Rodrigues EC, Machado MED, Cunha AL. Ser pai de um recém-nascido prematuro em unidade de terapia intensiva neonatal: da parentalidade a paternidade. Esc Anna Nery. 2015;19(3):409-16. http://dx.doi.org/10.5935/1414-8145.20150054.

5. Carvalho LS, Pereira CMC. As reações psicológicas dos pais frente à hospitalização do bebê prematuro na UTI neonatal. Rev SBPH [periódico na internet]. 2017; [citado 2019 mar 20];20(2):101-22. Disponível em: http://pepsic.bvsalud.org/scielo.php?script=sci_arttext\&pid=S151608582017000200007\&lng=pt

6. Soares NC, Bernardino MPL, Zani AV. Inserção do pai nos cuidados ao filho prematuro hospitalizado: percepção da equipe multiprofissional. Rev Paul Pediatr. 2019;37(3):283-90. http://dx.doi.org/10.1590/19840462/;2019;37;3;00014. PMid:31241689.

7. Bugs BM, Vieira CS, Rodrigues RM, Conterno SFR, Santos NT. Atividade educativa para mães de bebês prematuros como suporte para o cuidado. RECOM. 2018;8:e2725. http://dx.doi.org/10.19175/ recom.v8i0.2725

8. Martins ASD, Nascimento JDB, Santos IR, Silva JSL, Rêgo RMV, Andrade ASA et al. Participação do pai no método canguru: conhecimentos, dificuldades, motivações e sentimentos. Cad Grad Cienc Biol Saude [periódico na internet]. 2019 mar; [citado 2019 jul 16];5(2):95-106. Disponível em: https://periodicos.set.edu.br/index.php/cadernobiologicas/ article/view/6211/3222

9. Frigo J, Zocche DAA, Palavro GL, Turatti LA, Neves ET, Schaefer TM Percepções de pais de recém-nascidos prematuros em unidade de terapia intensiva neonatal. REUFSM. 2015;5(1):58-68. http://dx.doi. org/10.5902/2179769212900.

10. Vasconcelos JF, Xavier AT, Burgos TMR, Vasconcelos JF, Serrano SQ. Fotoetnografia como estratégia de ensino na visita perioperatória de enfermagem. Enf Rev [periódico na internet]. 2017; [citado 2019 jul 16];20(3):18-30. Disponível em: http://periodicos. pucminas.br/index.php/enfermagemrevista/article/view/17229 
11. Galvão MTG, Alexandre HO, Dantas PB, Lima ICV, Lopes EM. Uso da fotografia no processo do cuidar: tendências das ações de enfermagem. Ciencia y Enfermeria XIX. 2013;33(3):31-9. http://dx.doi.org/10.4067/ S0717-95532013000300004.

12. Souza MHN, Nespoli A, Zeitoune RCG. Influência da rede social no processo de amamentação: um estudo fenomenológico. Esc Anna Nery. 2016;20(4):e20160107. http://dx.doi.org/10.5935/1414-8145.20160107.

13. Jesus MCP, Capalbo C, Merighi MAB, Oliveira DM, Tocantins FR, Rodrigues BMRD et al. The social phenomenology of Alfred Schütz and its contribution for the nursing. Rev Esc Enferm USP.2013 jun;47(3):736-41. http://dx.doi.org/10.1590/S0080-623420130000300030. PMid:24601154

14. Sá No JA, Rodrigues BMRD. The intentional action of nursing team to caring for the newborn in the NICU. Ciênc Cuid Saúde. 2015;14(3):123744. http://dx.doi.org/10.4025/cienccuidsaude.v14i3.22320.

15. Instituto Nacional de Estudos e Pesquisas Educacionais Anísio Teixeira Dados de rendimentos, despesas e consumo [Internet]. Brasília: IBGE 2019 [citado 2020 Out 7]. Disponível em: https://www.ibge.gov.br/ estatisticas/sociais/rendimento-despesa-e-consumo.html

16. Kortchmar E, Merighi MAB, Conz CA, Jesus MCP, Oliveira DM. Reganho de peso após a cirurgia bariátrica: um enfoque da fenomenologia social. Acta Paul Enferm. 2018;31(4):417-22. http://dx.doi.org/10.1590/19820194201800058
17. Soares RLSF, Christoffel MM, Rodrigues EC, Machado MED, Cunha AL. Ser pai de recém-nascido prematuro na unidade de terapia intensiva neonatal: da parentalidade a paternidade. Esc Anna Nery. 2015;19(3):409-16. http://dx.doi.org/10.5935/14148145.20150054

18. Medeiros FB, Piccinini CA. Relação pai-bebê no contexto da prematuridade: gestação, internação do bebê e terceiro mês após a alta hospitalar Estud Psicol. 2015;32(3):475-85. http://dx.doi.org/10.1590/0103166X2015000300012.

19. Sisson H, Jones C, Williams R, Lachanudis L. Metaethnographic synthesis of fathers' experiences of the neonatal intensive care unit environment during hospitalization of their premature infants. JOGNN. 2015;44(4):471-80. http://dx.doi.org/10.1111/1552-6909.12662. PMid:26017337.

20. Ruiz N, Piskernik B, Witting A, Fuiko R, Ahnert L. Parent-child attachment in children born preterm and at term: A multigroup analysis. PLoS One. 2018;13(8):e0202972. http://dx.doi.org/10.1371/journal.pone.0202972. PMid:30161170.

21. Comaru NRC, Ramos IC, Silveira LC, Monteiro ARM. Teoria do relacionamento interpessoal em enfermagem e Fenomenologia Social de Alfred Schütz: propondo um diálogo. Braz J Dev. 2020;6(9):7013242. http://dx.doi.org/10.34117/bjdv6n9-458. 